\title{
Increasing Dynamic Stability of the Network Using Unified Power Flow Controller (UPFC)
}

\author{
K. Manoz Kumar Reddy \\ (Associate professor, Electrical and Electronics Department, Sriaditya Engineering College, India)
}

\begin{abstract}
The capability of increasing dynamic stability of the power system network by unified power flow controller (UPFC) is the main focus in this paper. Consequently, three control methods, namely, voltage control through shunt compensation, real power flow control through quadrature voltage injection and reactive power flow control through inphase voltage injection for the UPFC were examined inorder to improve the transient and dynamic stability of the power system. The quadrature voltage control was found to be effective in reducing the transient swings where as inphase voltage control was effective in improving the transient stability margin. Finally, the overall performance of the UPFC was evaluated in a single machine infinite bus system by nonlinear simulations, and results obtained showed the effectiveness of the controller in improving the dynamic stability of the system and provide better damping to electromechanical oscillations. Simulations were carried out using MATLAB and PSCAD software to check the performance of UPFC.
\end{abstract}

Keywords - Dynamic stability, infinite bus, real power, reactive power Unified power flow controller.

\section{INTRODUCTION}

With increasing demand of electric power, the existing transmission networks even in the developed countries are found to be weak which results in a poor quality of unreliable supply. In order to expand or enhance the power transfer capability of existing transmission network the concepts of FACTS (Flexible AC transmission system) is developed by the Electric Power Research Institute (EPRI) in the late 1980s. The main objective of facts devices is to replace the existing slow acting mechanical controls required to react to the changing system conditions by rather fast acting electronic controls. FACTs means alternating current transmissions systems incorporating power electronic based and other static controllers to enhance controllability and increase power transfer capability [1].

Unified Power Flow Controller (UPFC) is one of the FACTS devices, which can control power system parameters such as terminal voltage, line impedance and phase angle. Therefore, it can be used not only for power flow control, but also for power system stabilizing control. Unified power flow controllers are capable of directing real and reactive power flows through a designed route and regulating the system voltage through reactive power compensation. Thus, UPFC provides several features of power flow control namely voltage control through shunt compensation, real power flow through quadrature voltage injection and reactive power flow control through inphase voltage injection. Hence, the capability of transmission facilities can be better utilized. The mechanism of three control methods of UPFC in improving the transient stability of the power system will be examined .

Dynamic stability is the ability of power system to remain in synchronism after the initial swing or transient stability period until the system has settled down to the new steady state equilibrium condition. When sufficient time has elapsed after a disturbance, the governors of the primemovers will react to increase or decrease energy input, as may be required, to reestablish a balance between energy input and existing electrical load. This usually occurs in about 1 to 1.5 second after the disturbance. The period between the time the governors begin to react and the time that steady state equilibrium is reestablished is the period when dynamic stability characteristics of a system are effective. Dynamic stability studies cover longer real time intervals, perhaps 5-10 seconds, occasionally up to 30 seconds depending on the inertias of the system and the characteristics of the governors.

This paper investigates the three control methods namely, voltage control through shunt compensation, real power flow control through quadrature voltage injection and reactive power flow control through inphase voltage injection for the UPFC in order to improve the dynamic stability of the power system, thus providing the security for the increased power flow.

\section{OPERATION OF UPFC}

The basic components of the UPFC are the two voltage source converters sharing a common dc storage capacitor, and connected to the power system through the coupling transformers. One converter is connected to in shunt to the transmission system via a shunt transformer, while the other one is connected in series through a series transformer. A basic UPFC functional scheme is shown in Figure 1. 


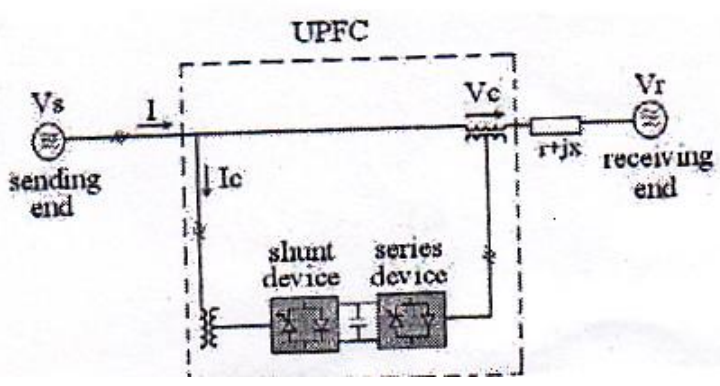

Fig 1: Basic functional scheme of UPFC

The series inverter is controlled to inject a symmetrical three phase voltage system, of controllable magnitude and phase angle in series with the line to control active and reactive Power flows on the transmission line [2]. So this inverter will exchange active and reactive power with the line. The reactive power is electronically provided by the series inverter and it is excited by dc link capacitor. The shunt converter is operated in such a way as to demand this dc terminal power from the line keeping the voltage across the storage capacitor $\mathrm{V}_{\mathrm{dc}}$ constant. So the net real power absorbed from the line by the UPFC is equal only to the losses of the converters and their transformers. The remaining capacity of the shunt converter can be used to exchange reactive power with the line so to provide the voltage regulation at the connection point [3].

\section{SYSTEM MODEL WITH UPFC}

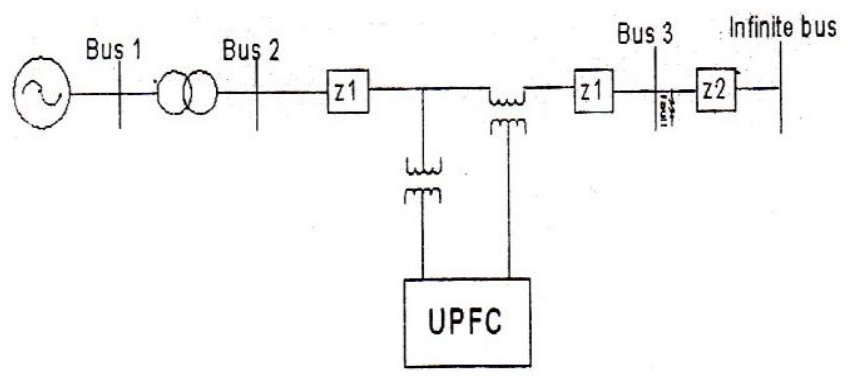

Fig 2 : Single machine infinite bus system with UPFC

A simple power system is chosen and studied in PSCAD/EMTDC environment in order to evaluate the performance of the UPFC with different control strategies. The power system whose parameters are given in appendix comprises a 100 MVA , $16.66 \mathrm{kV}$ synchronous generator connected to an infinite bus through a transmission line and a transformer stepping up the voltage to $330 \mathrm{kV}$. The generator is assumed to have Automatic Voltage Regulator (AVR) controlling its terminal voltage. The single machine infinite bus system (SMIB) used in this study is for better understanding of transient stability of the system. The UPFC is placed between bus 2 and bus 3 on the transmission line as shown in Figure 2. The UPFC is designed to control the power (real and reactive) through line as well as the voltage at bus 3 using PWM power controller.

\section{GENERATOR MODEL}

A detailed dynamic generator model for the single-machine infinite bus system is used for a UPFC controller design to give more accurate controller parameters. It is given as follows

$: \Delta \bar{S}^{\pi}(\mathrm{t})=w(\mathrm{t})$

$: w^{(t)}=-\left(\mathrm{D}_{\mathrm{m}} / 2 \mathrm{H}\right) w(\mathrm{t})+w_{\mathrm{o}} / 2 \mathrm{H}\left[\mathrm{P}_{\mathrm{m}}-\mathrm{P}_{\mathrm{e}}(\mathrm{t})\right]$

$: \Delta \mathrm{P}_{\mathrm{e}}(\mathrm{t})=\mathrm{P}_{\mathrm{e}}(\mathrm{t})-\mathrm{P}_{\mathrm{m}}$

Where $\Delta \delta(\mathrm{t})=\delta(\mathrm{t})-\delta_{\mathrm{o}}$ and $\delta(\mathrm{t})$ is the power angle of the generator; $\delta o$ is the power angle of the generator at the operating point; $w(\mathrm{t})$ is the relative speed of the generator; $\mathrm{P}_{\mathrm{m}}$ is the mechanical input power (assumed constant); $\mathrm{P}_{\mathrm{e}}(\mathrm{t})$ is the real power delivered by the generator; $w_{\mathrm{o}}$ is synchronous machine speed; $\mathrm{D}_{\mathrm{m}}$ is the per unit damping constant; $\mathrm{H}$ is the inertia constant

$$
E_{\mathrm{q}}^{\prime}(\mathrm{t})=1 / \mathrm{T}_{\mathrm{do}},\left[\mathrm{E}_{\mathrm{f}}(\mathrm{t})-\mathrm{E}_{\mathrm{q}}(\mathrm{t})\right]
$$

Where $\mathbb{E}_{\mathrm{q}}{ }^{\prime}(\mathrm{t})$ is derivative of the transient Electromotive force $(E M F)$ in the quadrature axis of the generator, $E_{q}(t)$ is the EMF in the quadrature axis; $E_{\mathrm{f}}(\mathrm{t})$ is the equivalent $\mathrm{EMF}$ in the excitation coil; $\mathrm{T}_{\mathrm{do}}$, is the direct axis open circuit transient time constant.

$$
\begin{aligned}
& : \mathrm{E}_{\mathrm{q}}(\mathrm{t})=\left(\mathrm{X}_{\mathrm{ds}} / \mathrm{X}_{\mathrm{ds}}^{\prime}\right) \mathrm{E}_{\mathrm{q}}^{\prime}(\mathrm{t})-\left[\left(\mathrm{X}_{\mathrm{d}}-\mathrm{X}_{\mathrm{d}}^{\prime}\right) / \mathrm{X}_{\mathrm{ds}}{ }_{\mathrm{s}}\right] \mathrm{V}_{\mathrm{E}} \cos \delta(\mathrm{t}) \\
& : \mathrm{P}_{\mathrm{e}}(\mathrm{t})=\left(\mathrm{V}_{\mathrm{E}} / \mathrm{X}_{\mathrm{ds}}\right) \mathrm{E}_{\mathrm{q}}(\mathrm{t}) \sin \delta(\mathrm{t}) \\
& : \mathrm{I}_{\mathrm{q}}(\mathrm{t})=\left(\mathrm{V}_{\mathrm{E}} / \mathrm{X}_{\mathrm{ds}}\right) \sin \delta(\mathrm{t})=\mathrm{P}_{\mathrm{e}}(\mathrm{t}) /\left(\mathrm{X}_{\mathrm{ad}} \mathrm{I}_{\mathrm{f}}(\mathrm{t})\right) \\
& : \mathrm{Q}(\mathrm{t})=\left(\mathrm{V}_{\mathrm{E}} / \mathrm{X}_{\mathrm{ds}}\right) \mathrm{E}_{\mathrm{q}}(\mathrm{t}) \cos \delta(\mathrm{t})-\mathrm{V}_{\mathrm{E}}{ }^{2} / \mathrm{X}_{\mathrm{ds}} \\
& : \mathrm{E}_{\mathrm{q}}(\mathrm{t})=\mathrm{X}_{\mathrm{ad}} \mathrm{I}_{\mathrm{f}}(\mathrm{t}) \\
& : \mathrm{X}_{\mathrm{ds}}=\mathrm{X}_{\mathrm{d}}+\mathrm{X}_{\mathrm{T}}+\mathrm{XL} / 4+\mathrm{X}_{\mathrm{E}}
\end{aligned}
$$

$$
: X^{\prime}{ }_{d s}=X^{\prime}{ }_{d}+X_{T}+X L / 4+X_{E}
$$

Where $\mathrm{E}_{\mathrm{q}}(\mathrm{t})$ is the transient Electromotive force (EMF) in the quadrature axis of the generator; $\mathrm{E}_{\mathrm{q}}(\mathrm{t})$ is the EMF in the quadrature axis; $Q(t)$ is the reactive power; $I_{f}(t)$ is the excitation current; $I_{q}(t)$ is the quadrature axis current; $X_{a d}$ is the mutual reactance between the excitation coil and the stator coil; $\mathrm{X}_{d}$ is the direct axis reactance of the generator; $\mathrm{X}_{d}^{\prime}$ is the direct axis transient reactance of the generator; $\mathrm{X}_{d s}^{\prime}$ is the mutual transient reactance between the direct axis of generator and transformer; $\delta(\mathrm{t})$ is the power angle of the generator; $\mathrm{X}_{\mathrm{ds}}$ is the mutual reactance between the direct axis of generator and transformer; $X_{T}$ is the reactance of the step up transformer; $X_{E}$ is the reactance of the Thevenin equivalent viewed from bus $\mathrm{V}_{1} ; \mathrm{V}_{\mathrm{E}}$ is the voltage magnitude of the Thevenin equivalent viewed from bus $\mathrm{V}_{1}$. 


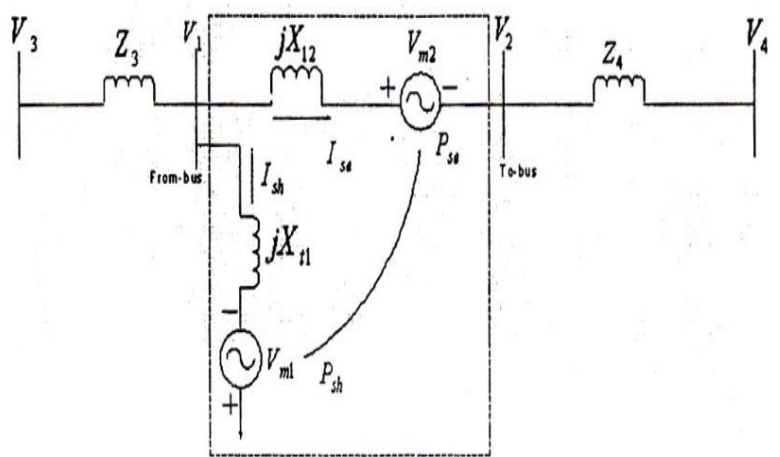

Fig 3: Model of UPFC

\section{UPFC MODEL AND CONTROL STRATEGIES}

The main function of UPFC is to inject an ac voltage with controllable magnitude and phase angle at the power frequency in series with the voltage and the transmission line via an insertion transformer. The mathematical UPFC model was derived with the aim of being able to study the relations between the electrical transmission system arid UPFC in steady-state conditions. The basic scheme of this model is shown in Figure 3. This figure represents a singleline diagram of a simple transmission line with impedance, UPFC, sending-end voltage source and receiving end voltage source. According to Figure 3, the power circulation and the line flow are calculated by the following expressions

: $\mathrm{P}_{\mathrm{sh}+} \mathrm{P}_{\mathrm{se}}=0$ neglecting losses

$: \mathrm{P}_{\mathrm{L}}=\mathrm{V}_{2}\left(\mathrm{~V}_{\mathrm{m} 2} \sin \left(\theta_{2}-\alpha_{2}\right)-\mathrm{V}_{1} \sin \left(\theta_{2}-\theta_{1}\right)\right) / \mathrm{X}_{\mathrm{t} 2}$

$: \mathrm{Q}_{\mathrm{L}}=-\mathrm{V}_{2}\left(\mathrm{~V}_{2}-\mathrm{V}_{1} \cos \left(\theta_{2}-\theta_{1}\right)+\mathrm{V}_{\mathrm{m} 2} \cos \left(\theta_{2}-\alpha_{2}\right)\right) / \mathrm{X}_{\mathrm{t} 2}$

Where $\mathrm{P}_{\mathrm{sh}}$ is the power at the shunt side of the UPFC; $\mathrm{P}_{\mathrm{se}}$ is the power at the series part of UPFC; $\mathrm{P}_{\mathrm{L}}$ is the real power flow; $\mathrm{Q}_{\mathrm{L}}$ is the reactive power flow; $\mathrm{V}_{2}$ is the voltage at the bus $2 ; \mathrm{V}_{\mathrm{m} 2}$ is the series voltage of UPFC; $\mathrm{V}_{1}$ is the voltage at bus $1 ; \mathrm{X}_{\mathrm{t} 2}$ is the reactance between buses 1 and 2 ; $\theta_{1}$ and $\theta_{2}$ are the angles of buses 1 and 2 respectively.

Consider $\mathrm{V}_{\mathrm{m} 2 \mathrm{p}}$ and $\mathrm{V}_{\mathrm{m} 2 \mathrm{q}}$ are the components of the series voltage of UPFC. They are proportional to the voltage at the point of connection of UPFC and can be written as

$: \mathrm{V}_{\mathrm{m} 2 \mathrm{p}}=\mathrm{V}_{2} \gamma(\mathrm{t})$ and $\mathrm{V}_{\mathrm{m} 2 \mathrm{q}}=\mathrm{V}_{2} \beta(\mathrm{t})$

where $\beta(\mathrm{t})$ and $\gamma(\mathrm{t})$ are the control variables. And also

$: \mathrm{V}_{2}+\mathrm{V}_{\mathrm{m} 2 \mathrm{q}}+\mathrm{X}_{\mathrm{t} 2} \mathrm{I} \sin \varphi=\mathrm{V}_{3} \cos \delta$

$: \mathrm{V}_{\mathrm{m} 2 \mathrm{p}}+\mathrm{X}_{\mathrm{t} 2} \mathrm{I} \cos \varphi=\mathrm{V}_{3} \sin \delta$

Multiplying by $\mathrm{V}_{2}$ to above two equations ( $\left.16 \& 17\right)$
: $\mathrm{P}_{2}=\left(\mathrm{V}_{2} \mathrm{~V}_{3 /} \mathrm{X}_{\mathrm{t} 2}\right) \sin \delta-\left(\mathrm{V}_{2} \mathrm{~V}_{\mathrm{m} 2 \mathrm{p}} / \mathrm{X}_{\mathrm{t} 2}\right)$

$: \mathrm{Q}_{2}=\left(\mathrm{V}_{2} \mathrm{~V}_{3 /} \mathrm{X}_{\mathrm{t} 2}\right) \cos \delta-\left(\mathrm{V}_{2} \mathrm{~V}_{\mathrm{m} 2 \mathrm{q}} / \mathrm{X}_{\mathrm{t} 2}\right)-\left(\mathrm{V}_{2}^{2} / \mathrm{X}_{\mathrm{t} 2}\right)$

The partial derivatives are calculated as respectively

$$
\begin{aligned}
& : \mathrm{dP}_{2} / \mathrm{dt}=\left(ð \mathrm{P}_{2} / \partial \delta\right)(\mathrm{d} \delta / \mathrm{dt})+\left(ð \mathrm{P}_{2} / \partial \mathrm{V}_{\mathrm{m} 2 \mathrm{p}}\right)\left(\mathrm{dV}_{\mathrm{m} 2 \mathrm{p}} / \mathrm{dt}\right) \\
& : \mathrm{dQ}_{2} / \mathrm{dt}=\left(ð \mathrm{Q}_{2} / ð \delta\right)(\mathrm{d} \delta / \mathrm{dt})+\left(ð \mathrm{Q}_{2} / ð \mathrm{~V}_{\mathrm{m} 2 \mathrm{q}}\right)\left(\mathrm{dV}_{\mathrm{m} 2 \mathrm{q}} / \mathrm{dt}\right)
\end{aligned}
$$

Therefore, modulation controller for series-injected voltage can be designed by using (20) and (21). The value of $\mathrm{K}$ is chosen so that the injected series voltage remains at its nominal value. The values of $V_{2}$ and $V_{3}$ can be chosen as 1.0 per unit(p.u). The injected series voltage, $\mathrm{V}_{\mathrm{m} 2}$ is calculated as

$: \mathrm{V}_{\mathrm{m} 2}=\left(\mathrm{V}_{\mathrm{m} 2 \mathrm{p}}{ }^{2}+\mathrm{V}_{\mathrm{m} 2 \mathrm{q}}{ }^{2}\right)^{0.5}$

And $\delta=\tan ^{-1}\left(\mathrm{~V}_{\mathrm{m} 2 \mathrm{p}} / \mathrm{V}_{\mathrm{m} 2 \mathrm{q}}\right)$

UPFC can be controlled in a variety of ways to meet different objectives. Basically, UPFC has two different control strategies, namely, (1) series compensator consisting of series inverter and series transformer modeled as a fully controllable voltage source which controls the real and reactive power flow through the transmission line. (2) Shunt compensator comprising shunt inverter, shunt transformer and connection filter modeled as a fully controllable voltage source with connection impedance including the leakage of the shunt transformer.

The series inverter provides the main function of the UPFC by injecting a voltage with magnitude, $\mathrm{V}_{\mathrm{m} 2}$ which is controllable and a phase angle $\delta$ in series with the line via an insertion transformer. This injected voltage acts essentially as a synchronous ac voltage source. The transmission line current flows through this voltage source resulting in a reactive and active power exchange between itself and the ac system. The inverter generates the reactive power exchanged at the ac terminal internally. The active power exchanged at the ac terminal is converted into dc power, which appears at the dc link as a positive or negative real power.

The basic function of shunt inverter is to generate or absorb the real power demanded by series inverter at the common dc link [4]. The power demand by the series inverter at the dc link is converted back to ac by the shunt inverter and fed to the transmission line bus via a shuntconnected transformer. In addition to this the shunt inverter can also generate or absorb controllable reactive power if desired and thereby provides independent shunt reactive compensation for the line [5].

then we get 


\section{SIMULATION RESULTS}

To test the effectiveness of the UPFC controller, a balanced three-phase fault is applied to the line at the end close to bus 3 (see Figure 1) at $5.0 \mathrm{~s}$ when the generator is operating at its rated power level. The duration of the fault is $0.10 \mathrm{~s}$. The system responses are simulated using PSCAD/EMTDC . Figures 4 to 12 show the system responses with and without UPFC. It can be observed from these figures that the UPFC can greatly improve the damping of the system and its stability. The equations used in the simulation were from 1 to 11 and $13 \& 14$.

The simulation results of shunt compensation are shown in Figure 4 to Figure 6. It is observed that the dynamic oscillations in Figure 4 are well damped when UPFC is connected to the system, although they have large first swing after the fault is cleared. From Figures 5 and 6, it can be seen that the real and reactive power could be controlled to a specific value after the fault is cleared, which shows that the UPFC is very effective in line flow control. This, of course, limits the electrical power output of the generator which makes the rotor angle increase more than that when there is no UPFC.

The two components of series compensation control are considered with respect to the injected voltage. These components are in-phase voltage and quadrature voltage. The simulation results of the quadrature voltage control are as shown in Figures 7 to 11 . It is observed that the transient swings are reduced, but it is poor in load flow control and damping control..

However, from the equal area criterion, it can be predicted that after the rotor angle reaches the maximum value in the first swing, this control strategy should be changed and should be aiming at damping of the subsequent swings. But, with in-phase voltage control, the transient stability margin is significantly improved (see Figure 12).

It is noteworthy that the in-phase component contributes to the real power exchange between the series and shunt branch of the UPFC, and reduces the fluctuation in capacitor voltage at its zero value.

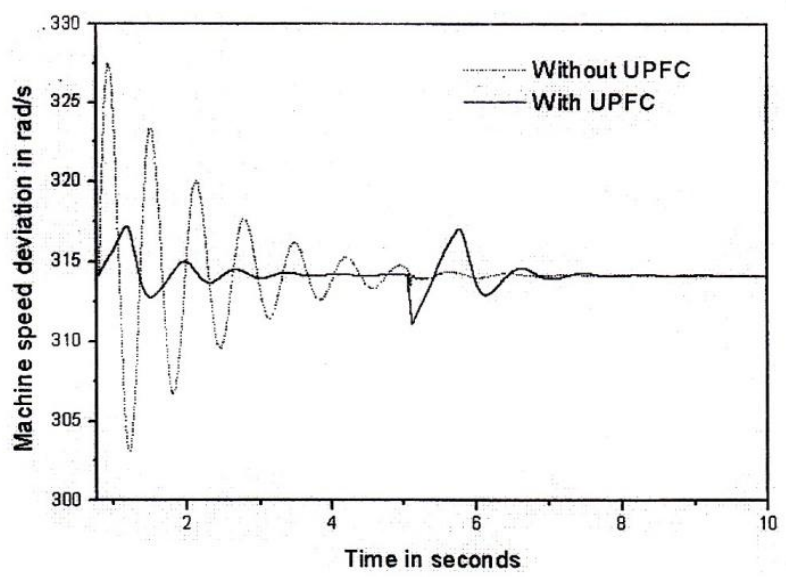

Fig 4: speed response of synchronous generator

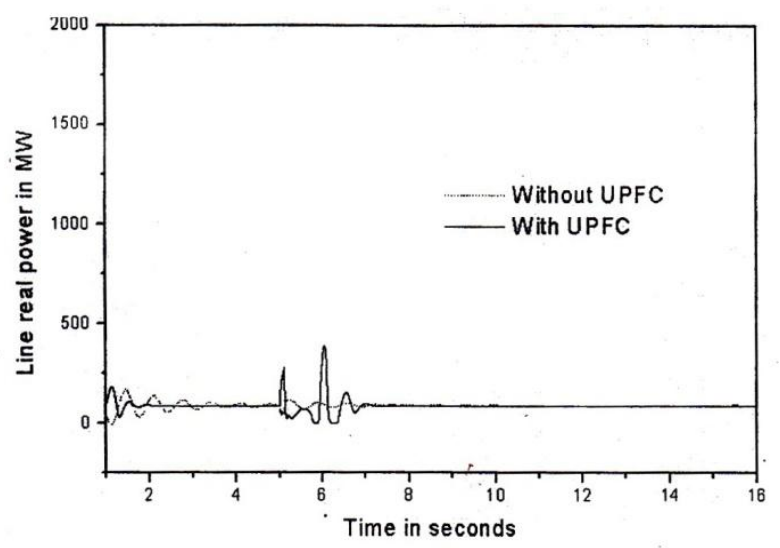

Fig 5 : Transient corresponding to line real power

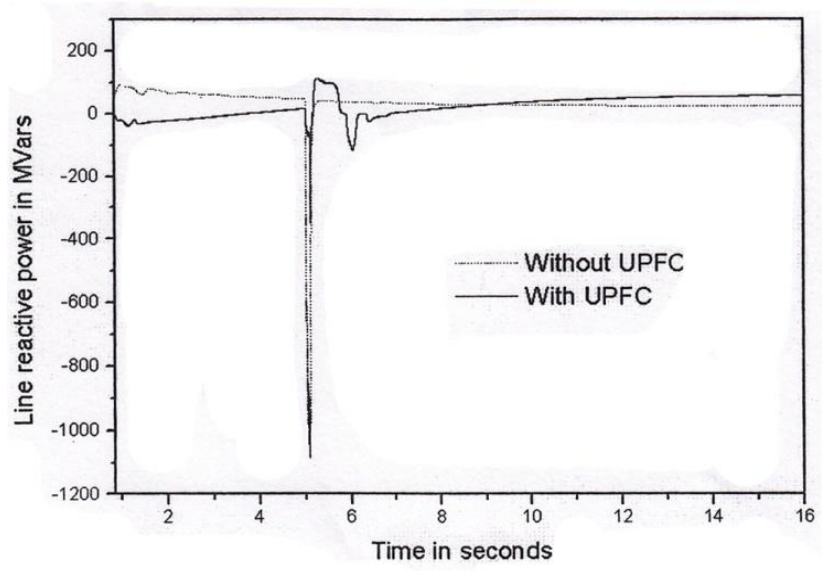

Fig 6: Transient corresponding to line reactive power

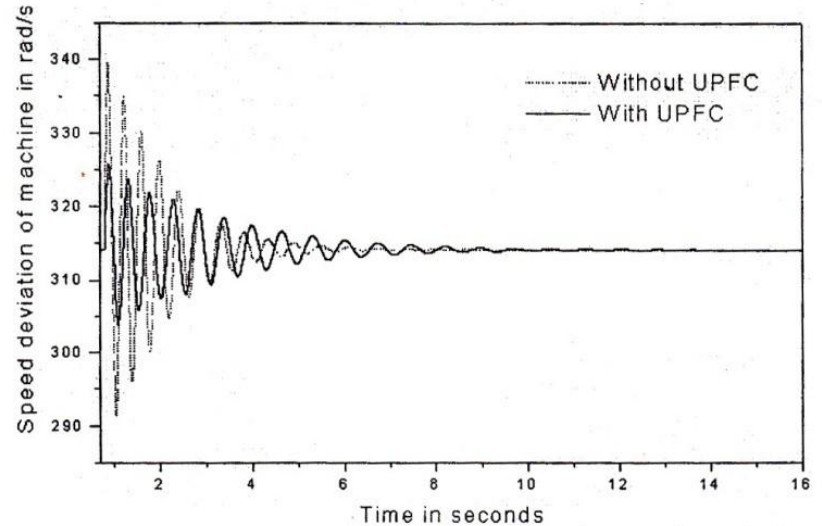

Fig 7:Speed response by quadrature voltage control 


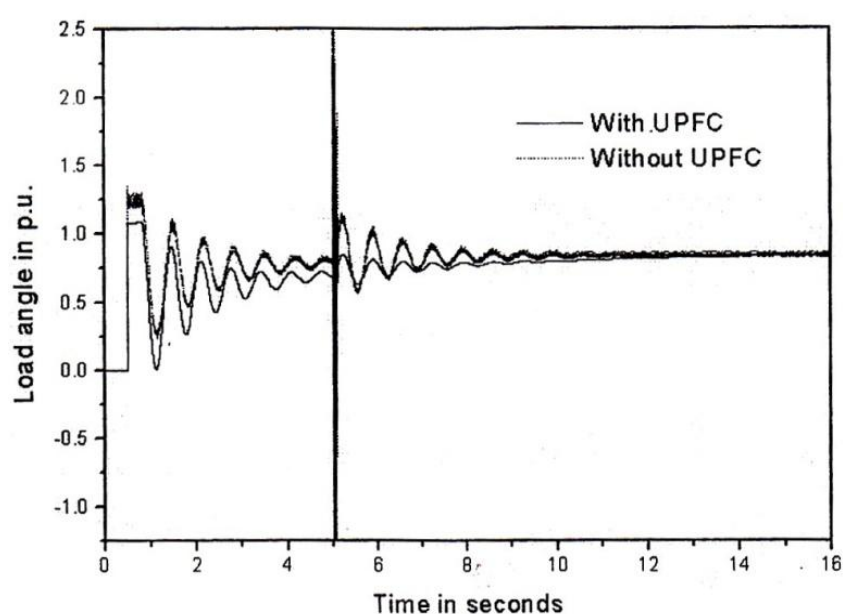

Fig 8: Load angle response by quadrature voltage control

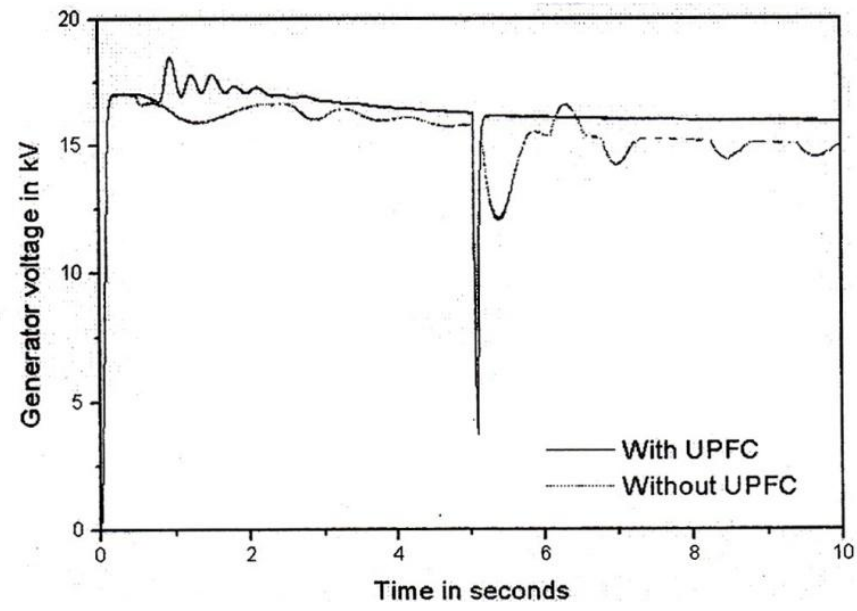

Fig 9: Terminal voltage response by quadrature voltage Control

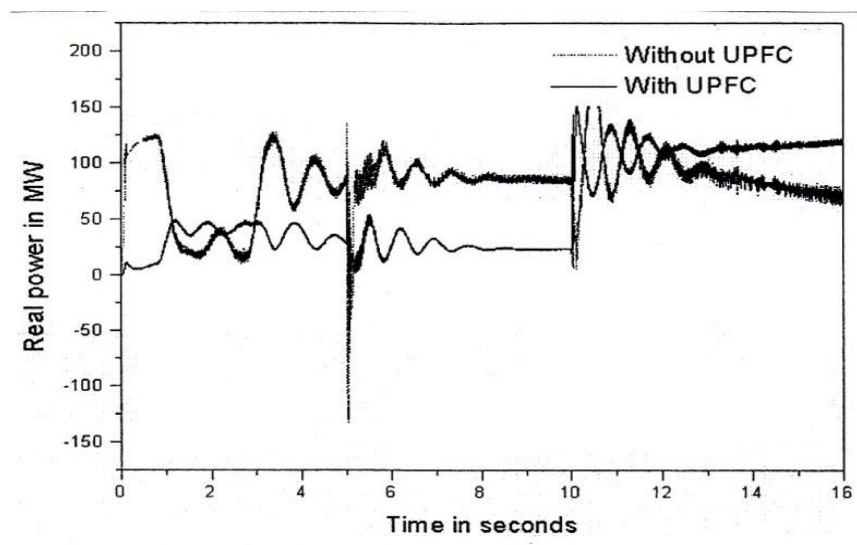

Fig 10: Line real power transient by quadrature voltage control

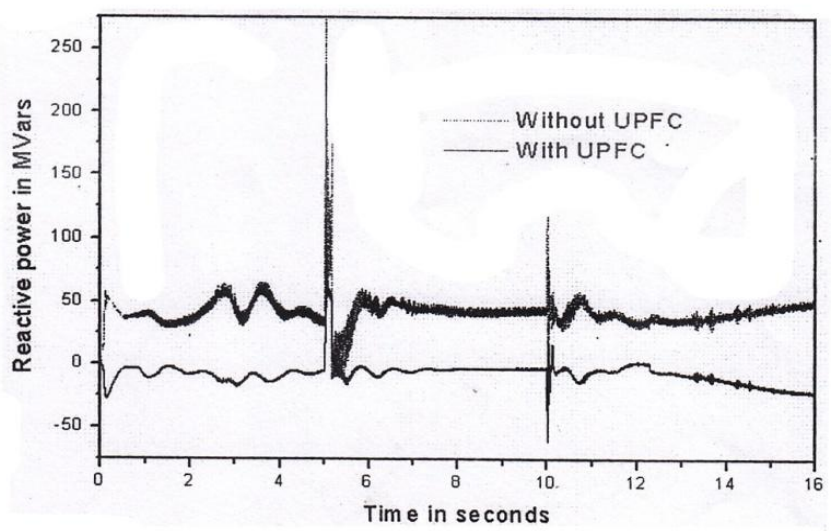

Fig 11: Line reactive power transient by quadrature voltage control

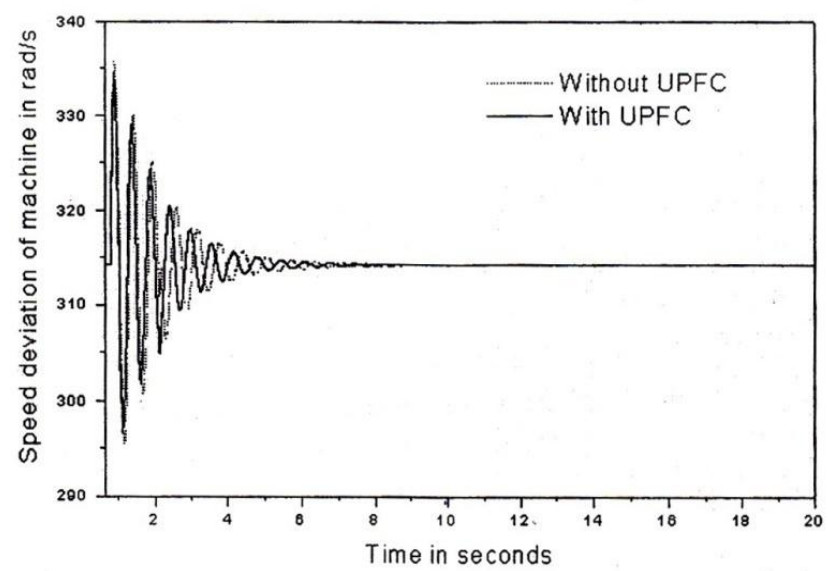

Fig 12: Improved transient stability margin by inphase voltage control

\section{APPENDIX}

The power system network used in this work is having the following ratings.

Table 1. Generator ratings

\begin{tabular}{|l|l|}
\hline Rated power & $100 \mathrm{MVA}$ \\
\hline Rated voltage & $16.66 \mathrm{KV}$ \\
\hline Rated current & $3.47 \mathrm{KA}$ \\
\hline Inertia constant $\mathrm{H}$ & $3.12 \mathrm{~s}$ \\
\hline Frequency & $50 \mathrm{~Hz}$ \\
\hline
\end{tabular}


IOSR Journal of Engineering

Apr. 2012, Vol. 2(4) pp: 744-749

Table 2. Main transformer ratings

\begin{tabular}{|c|c|}
\hline MVA rating & $1000 \mathrm{MVA}$ \\
\hline Frequency & $50 \mathrm{~Hz}$ \\
\hline $\begin{array}{c}\text { Primary/secondary } \\
\text { ratings }\end{array}$ & $16 \mathrm{KV} / 330 \mathrm{KV}$ \\
\hline Leakage reactance & $0.01932 \mathrm{p} . \mathrm{u}$ \\
\hline
\end{tabular}

Table 3. Shunt and series transformer ratings

\begin{tabular}{|c|l|}
\hline $\begin{array}{c}\text { Shunt transformer } \\
\text { ratings }\end{array}$ & $\begin{array}{l}330 \mathrm{KV} / 20 \mathrm{KV}, 300 \\
\mathrm{MVA}\end{array}$ \\
\hline $\begin{array}{c}\text { Series transformer } \\
\text { ratings }\end{array}$ & $\begin{array}{c}20 \mathrm{KV} / 33 \mathrm{KV}, \quad 100 \\
\mathrm{MVA}\end{array}$ \\
\hline DC link voltage $\mathrm{V}_{\mathrm{dc}}$ & $20 \mathrm{KV}$ \\
\hline Capacitance & $2000 \mu \mathrm{F}$ \\
\hline
\end{tabular}

VIII. CONCLUSION

In this paper, the capability of regulating power flow in a Single-machine Infinite bus system using UPFC has been investigated. The mechanism of the three control methods, namely, in-phase voltage control, quadrature voltage control and shunt compensation was also examined in improving the transient and dynamic stability of the power system and these three control methods were separately considered in this work. The quadrature voltage control was found to be effective in reducing the transient swings whereas in-phase voltage control was effective in improving the transient stability margin. The performance of the UPFC model and has been evaluated in a single-machine infinite bus system by nonlinear simulations. The results show that the controller significantly improves transient and also mainly dynamic stability of the system and provides better damping to electromechanical oscillations.

\section{REFERENCES}

[1] L.gyugi, A unified power flow concept for flexible AC transmission systems, IEEE proc.c 139(4)1992.

[2] K.R.Padiyar and K.uma rao, Modelling and control of unified power flow controller for transient stability, Electrical power and energy systems, vol 21 (1999) 111.

[3] H.f.wang, Interactions and multi variable design of unified power flow controller, electrical power and energy systems 24(2002).

[4] A.W.Green,J.T.Boys, Threephase voltage sourced reversible rectifiers, IEEE proc.135(1988)362-370.

[5] K. Manoz kumar reddy, simulation of unified power flow controller, proceedings of National conference on recent trends in power systems and power electronics,( Feb 2012)148-151. 